\title{
Cytogenetic analysis of reciprocal hybrids and their parents between Larix leptolepis and Larix gmelinii: implications for identifying hybrids
}

\author{
Shou Gong Zhang • Wen Hua Yang • Su Ying Han • \\ Bo Tao Han • Mao Xue Li • Li Wang Qi
}

Received: 8 February 2009/Revised: 16 August 2009/Accepted: 23 November 2009 / Published online: 19 January 2010

(C) The Author(s) 2010. This article is published with open access at Springerlink.com

\begin{abstract}
We studied the parental taxa and the interspecific reciprocal hybrids between Larix leptolepis with Larix gmelinii, using classical cytogenetic methods, as well as fluorescence in situ hybridization (FISH) and genomic in situ hybridization. A high frequency $(>90 \%)$ of complete bivalent formation was observed in reciprocal hybrids. Less than $10 \%$ of pollen mother cells exhibited abnormalities. The most frequent abnormalities were bridges. Multivalent chromosome associations were also observed in both reciprocal hybrids, suggesting that some chromosome interchange events did occur, and introgressions from one to the other species were possible. Intergenomic recombination indicates that genes might be readily introgressed into one species from the other in the genus Larix. Interspecific hybridization may be a potential method for genetic
\end{abstract}

Communicated by R. Sederoff

Shou Gong Zhang and Wen Hua Yang have contributed equally to this work.

S. G. Zhang • W. H. Yang $\cdot$ L. W. Qi $(\bowtie)$

Laboratory of Cell Biology, The Research Institute of Forestry,

Chinese Academy of Forestry,

100091 Beijing, People's Republic of China

e-mail: lwqi@caf.ac.cn

S. Y. Han

Key Laboratory of Research Institute of Forest Ecology and Protection,

Chinese Academy of Forestry,

100091 Beijing, China

B. T. Han

College of Biological Sciences and Biotechnology,

Beijing Forestry University,

100083 Beijing, China

M. X. Li

College of Life Sciences, Peking University,

100871 Beijing, China improvement in larch. FISH markers documented that the recombinant genomes of reciprocal hybrids were strictly additive and stable, indicating that FISH also might be a useful tool in Larix breeding.

Keywords Forest tree hybrids · In situ hybridization · Larix . Meiosis $\cdot$ Pollen mother cells

\section{Introduction}

Larch species $\left(2 n=2 x=24,1 \_\mathrm{C}=12.53 \mathrm{pg}\right.$, http://data.kew. org/cvalues/CvalServlet?querytype $=4$ ) can easily be hybridized, and morphological and genetic studies indicate that hybridization is also widespread in natural populations (Kruklis and Milyutin 1977; Semerikov et al. 1999). Interspecific hybridization is an important process in the evolution of plant species (Rieseberg 1997) but also a source for the creation of genetic variability for breeding improvement (Desel et al. 2002). Various hybrids deriving from crosses between species of the Larix genus often have many attractive features such as faster juvenile growth, higher volume productivity, and greater survival than either parental species (Baltunis et al. 1998; Pâques 1992, 2002). Therefore, interspecific hybridization should provide the opportunity to access economic and other interesting traits for genetic improvement of the larch.

Larix leptolepis is an exotic reforestation species in many countries because of its fast juvenile growth and wide adaptation to severe environmental stress sites (Mikami 1988). However, this species is susceptible to various sorts of pests and diseases (Hayashi et al. 1998). Larix gmelinii, a main component of the Great Xingan Mountains forest in northeast of China, is also considered in larch breeding programs for its tolerance of chilling stress. Some of these 
hybrid lines often combine interesting traits of both parental species, i.e., fast juvenile growth from $L$. leptolepis together with cold hardness from $L$. gmelinii. However, little is known about the genomes and meiotic chromosome behavior in interspecific Larix hybrids.

A better understanding of the genomes and meiotic chromosomal behavior in interspecific Larix hybrids will benefit larch breeding programs. The specific objective of this research was to evaluate the genome relationship between L. leptolepis and L. gmelinii, and to investigate the cytogenetics and meiotic behaviors of reciprocal interspecific hybrids between the two species.

\section{Materials and methods}

\section{Plant materials}

In 1979, reciprocal interspecific hybrids between $L$. leptolepis with L. gmelinii were established at Dagujia Forestry Center in Liaoning Province, China. The obtained hybrids have been grown there since. Three genotypes each species and one pair of reciprocal hybrids of each cross were selected. Seeds of their parents and young needles of hybrids were collected in 2007.

For meiotic studies, cones were collected and fixed in 3:1 absolute ethanol and glacial acetic acid at room temperature for $24 \mathrm{~h}$, transferred to $70 \%$ alcohol, and stored under refrigeration until use. The anthers were dissected out and squashed on microscopic slides in the medium of $45 \%$ acetic acid for fluorescence in situ hybridization (FISH) or $1.5 \%$ carbolic acid-fuchsin solution for observations of chromosome pairing.

\section{Chromosome preparation}

Seeds were germinated in the dark on water-saturated filter paper at $25^{\circ} \mathrm{C}$ for 2 weeks. Root tips or young needles were submerged in $0.5 \%(w / v)$ aqueous colchicinefor $24 \mathrm{~h}$ at room temperature and fixed overnight at $4{ }^{\circ} \mathrm{C}$ in $3: 1$ ethanol: acetic acid. Then, root tips were rinsed in $0.01 \mathrm{M}$ sodium citrate/citric acid buffer and digested in $2 \%$ cellulase, $1 \%$ macerase, and $2 \%$ liquid pectinase for $1 \mathrm{~h}$ at $37^{\circ} \mathrm{C}$. After squashing in $45 \%$ acetic acid, the coverslip was removed after freezing in liquid nitrogen, and the slides were dehydrated by consecutive immersion in $75 \%, 95 \%$, and $100 \%$ ethanol, and were then air-dried and stored in a freezer at $-70^{\circ} \mathrm{C}$. The better preparations were identified by phase contrast Olympus BX51 microscopy.

Probe DNA labeling

Double FISH was carried out with two DNA probes. The DNA probe JDH 2-15A, containing an 8.2-kb Xho1 fragment, was kindly provided by Drs. Dai and $\mathrm{Wu}$ (Cornell University). The insert of $8.2 \mathrm{~kb}$ Xhol fragment contains almost a full Arabidopsis rDNA repeat. The probe was labeled by means of high random prime with biotin-16dUTP following the supplier's instructions (Roche, Germany), and the second probe, 5S rDNA probe, was obtained by polymerase chain reaction (PCR). The primers for 5S rDNA amplification were 5'-CGGTGCAT TAATGCTGGTAT and 5'-CCATCAGAACTCCGA-3'. The PCR program for 5S rDNA amplification consisted of $3 \mathrm{~min}$ at $94^{\circ} \mathrm{C}$ for initial denaturation followed by 30 cycles of $30 \mathrm{~s}$ at $94^{\circ} \mathrm{C}, 30 \mathrm{~s}$ at $53^{\circ} \mathrm{C}$, and $30 \mathrm{~s}$ at $72^{\circ} \mathrm{C}$. In the last cycle, the extension at $72^{\circ} \mathrm{C}$ was extended to $5 \mathrm{~min}$. The PCR products were cloned into a plasmid vector (pGEM-1, Promega) and sequenced in both directions using an ABI 377 automatic sequencer. The 5S rDNA probe was labeled by PCR in a 50-ul reaction volume in the presence of digoxigenin-11-dUTP using the same PCR primers.

Genomic DNA was extracted from 50 to $100 \mathrm{mg}$ young needles of Larix species using the method of Doyle and Doyle (1990). Genomic DNA probes were labeled with Dig High Prime (Boehringer Mannheim, Germany), according to the manufacturer's procedures. Genomic in situ hybridization (GISH) was performed on meiotic chromosomes of the F1 hybrids between L. leptolepis with L. gmelinii.

\section{Fluorescence in situ hybridization}

FISH was performed following the procedures described by Leitch et al. (1994) with several modifications. Slides with cell spreads were incubated in $100 \mathrm{ug} \mathrm{m}^{-1}$ DNase-free RNase $\mathrm{A}$ in $2 \times$ standard saline citrate $(\mathrm{SSC})$ at $37^{\circ} \mathrm{C}$ for $1 \mathrm{~h}$, washed twice in $2 \times \mathrm{SSC}$ for $10 \mathrm{~min}$ at room temperature, refixed in freshly depolymerized $4 \%(w / v)$ paraformaldehyde in water for $5 \mathrm{~min}$ at room temperature, and washed in $2 \times \mathrm{SSC}$ for $5 \mathrm{~min}$. The slides were dehydrated in a series of $70 \%, 95 \%$, and $100 \%$ ethanol and then air-dried. The probe solution, consisting of labeled DNA (100 ng ml-1) in a solution of unlabelled blocking DNA $\left(5 \mathrm{ug} \mathrm{ml}^{-1}\right), 50 \%(v / v)$ deionized formamide, $10 \%$ $(w / v)$ dextran sulphase, $0.1 \%(w / v)$ sodium dodecyl sulfate (SDS), and $2 \times \mathrm{SSC}$, was denatured at $97^{\circ} \mathrm{C}$ for $10 \mathrm{~min}$, $10 \mathrm{ul}$; the probe mix was quenched on ice for $10 \mathrm{~min}$ and then loaded onto slides with cell spreads and covered with a coverslip. The slides were wrapped with preservative film and then were transferred to a humid chamber and denatured at $90^{\circ} \mathrm{C}$ for $10 \mathrm{~min}$, then immediately put into a hybridization oven and hybridized at $37^{\circ} \mathrm{C}$ overnight.

Detection of hybridization

After hybridization, slides were then washed twice in $2 \times \mathrm{SSC}$ containing $1 \% \mathrm{SDS}$ for $5 \mathrm{~min}$ at $42^{\circ} \mathrm{C}, 2 \times \mathrm{SSC}$ for 
$5 \mathrm{~min}$ at $42^{\circ} \mathrm{C}$, and $2 \times \mathrm{SSC}$ for $5 \mathrm{~min}$ at room temperature. The slides were washed a final time for $5 \mathrm{~min}$ in $2 \times \mathrm{SSC}$ containing $0.2 \%$ Tween-20. DIG-labeled probes were detected using Rodamine diluted 1:2,000 in detection buffer. The DIG-labeled signals (5S rDNA sites) were detected using anti-DIG-FITC (Roche), and the biotinlabeled signals (45S rDNA sites) were detected using strepetavidin-Cy3 (Sigma). The antibody binding reaction was carried out at $37^{\circ} \mathrm{C}$ in $5 \%$ bovine serum albumin (BSA) in $2 \times \mathrm{SSC}$ containing $0.2 \%$ Tween-20 for about $1 \mathrm{~h}$. The slides were washed three times in $5 \%$ BSA in $2 \times \mathrm{SSC}$ containing $0.2 \%$ Tween-20 for $5 \mathrm{~min}$ each at $37^{\circ} \mathrm{C}$. Finally, chromosomal DNA was counterstained for 3-5 $\mathrm{min}$ in $0.5 \mathrm{ug} / \mathrm{ml}$ of $4^{\prime}, 6$-diamidino-2-phenylindole (DAPI) in phosphate-buffered saline (PBS; $\mathrm{pH} 7.4$ ), rinsed in $1 \times \mathrm{PBS}$, and mounted with anti-fade solution (Vector Laboratories Inc., Burlingame, CA, USA).

All images were captured with an Olympus BX51 phase/fluorescence microscope equipped with a cooled CCD camera and processed by Adobe Photoshop 7.0 software.

\section{Results}

\section{Chromosomal distribution of rDNA loci}

Both the interspecific hybrid and its reciprocal contained the expected chromosome number $(2 n=2 x=24$; Fig. 1a, b). FISH localization of the $45 \mathrm{~S}$ rDNA genes differentiated the two parental species by the number of rDNA sites. L. leptolepis had two pairs of $45 \mathrm{~S}$ rDNA signals (Fig. 1a), whereas $L$. gmelinii had three pairs of $45 \mathrm{~S}$ rDNA signals (Fig. 1b). When the $45 \mathrm{~S}$ rDNA probe was hybridized to mitotic cells of the two hybrids, five fluorescence signals were observed, as expected, in all accession cells of these two hybrids. Thus, we concluded that the FISH signals of $45 \mathrm{~S}$ rDNA repetitive sequences in both parents were different, and in the hybrids, the signals were exactly additive (red signals in Fig. 1c, d).

Only one 5S rDNA locus was detected within each genome of the two parental and hybrid species and was co-localized with a $45 \mathrm{~S}$ rDNA, giving a strong double-hybridization signal that allowed this chromosome to be readily identified (green signals in Fig. 1). The distribution patterns of the two types of rDNA genes appeared similar in the three genomes, indicating conservation of the chromosomal position of the rDNA within both parental genomes.

\section{Meiotic behavior}

Cytological analysis of meiosis in the parental species revealed over $97 \%$ of the meiocytes showed regular bivalent chromosome pairing; however, several meiotic irregularities, such as ascending, anaphase bridges, and multivalent pairing, were occasionally observed, whose type and frequency are presented in Table 1.

The general features of the meiotic behavior of the reciprocal hybrids are also summarized in Table 1. Irrespective of the maternal parents, the patterns of meiotic configurations of reciprocal hybrids were fairly similar (Table 1). A high frequency ( $>90 \%$ ) of complete bivalent formation was observed in reciprocal crosses (Fig. 2a, b), indicating that the genomes of L. leptolepis and L. gmelinii were highly homologous. Our results, moreover, showed that less than $10 \%$ of pollen mother cell exhibited abnormalities, such as multivalents (Fig. 2c, d), univalents (Fig. 2e, f), and irregular chromosome segregation (ascending, laggard, and bridge; Fig. 2g-i). Multivalents were relatively rare (Fig. 2c), and some trivalents have a "fryingpan" (a ring bivalent connected to a rod univalent) appearance (Fig. 2d), indicating that some chromosome interchange events did occur. A few unpaired univalents were observed (Fig. 2e, f) owing to the lack of chromosome pairing. In anaphase-I, they moved randomly to opposite poles (Fig. 2g-i). Irregular chromosome segregation was the main problem found in meiosis I. The most frequent configuration was chromatin bridges in anaphase-I (Fig. 2g), which accounted for $14 \%$ and $16 \%$ of the anaphase-I cells of L. leptolepis $\times L$. gmelinii and $L$. gmelinii $\times$ L. leptolepis, respectively (Table 1 ). Due to the high frequency of bridges, segregation was irregular at anaphase-I (Fig. 2h, i). These irregular misdivisions may lead to telocentrics or isochromosomes. Ascending and laggard chromosomes were also observed at telophase-I in some cells (Fig. $2 \mathrm{~g}-\mathrm{i}$ ), which could result in gametes with various chromosome numbers because of unequal chromosome migration, segregation, and allocation in daughter cells. However, the imbalanced distribution of chromosomes in anaphase-I did not persist up to the second division, in which chromatids were split normally into daughter nuclei (data not shown), suggesting a strong selection against abnormal meiotic products in early stages.

To better characterize the genomic changes in hybrids, we traced the behaviors of the rDNA containing chromosomes as a cytogenetic markers for potential genomic processes of these reciprocal hybrids by FISH. In the present work, we found homoeologous chromosomes exclusively forming bivalents in most meiotic cells of these reciprocal hybrids based on the distribution of $45 \mathrm{~S}$ and $5 \mathrm{~S}$ rDNA at diakinesis/metaphase-I (Fig. 3a, b), suggesting that homoeologous bivalents were formed at a relatively high rate. Regular homoeologous pairing in the hybrids insured proper segregation of chromosomes. Figure 3, c and $\mathrm{d}$, show that two pairs of chromosomes possessing the 
Fig. 1 Physical mapping of 45S rDNA (red) and 5S rDNA (green) to somatic metaphase chromosomes, and chormosomes were counterstained with DAPI (blue). a Larix leptolepis. b Larix gmelinii. c L. leptolepis $\times$ L. gmelinii. d $L$. gmelinii $\times$ L. leptolepis. Scale bar $=15$ um
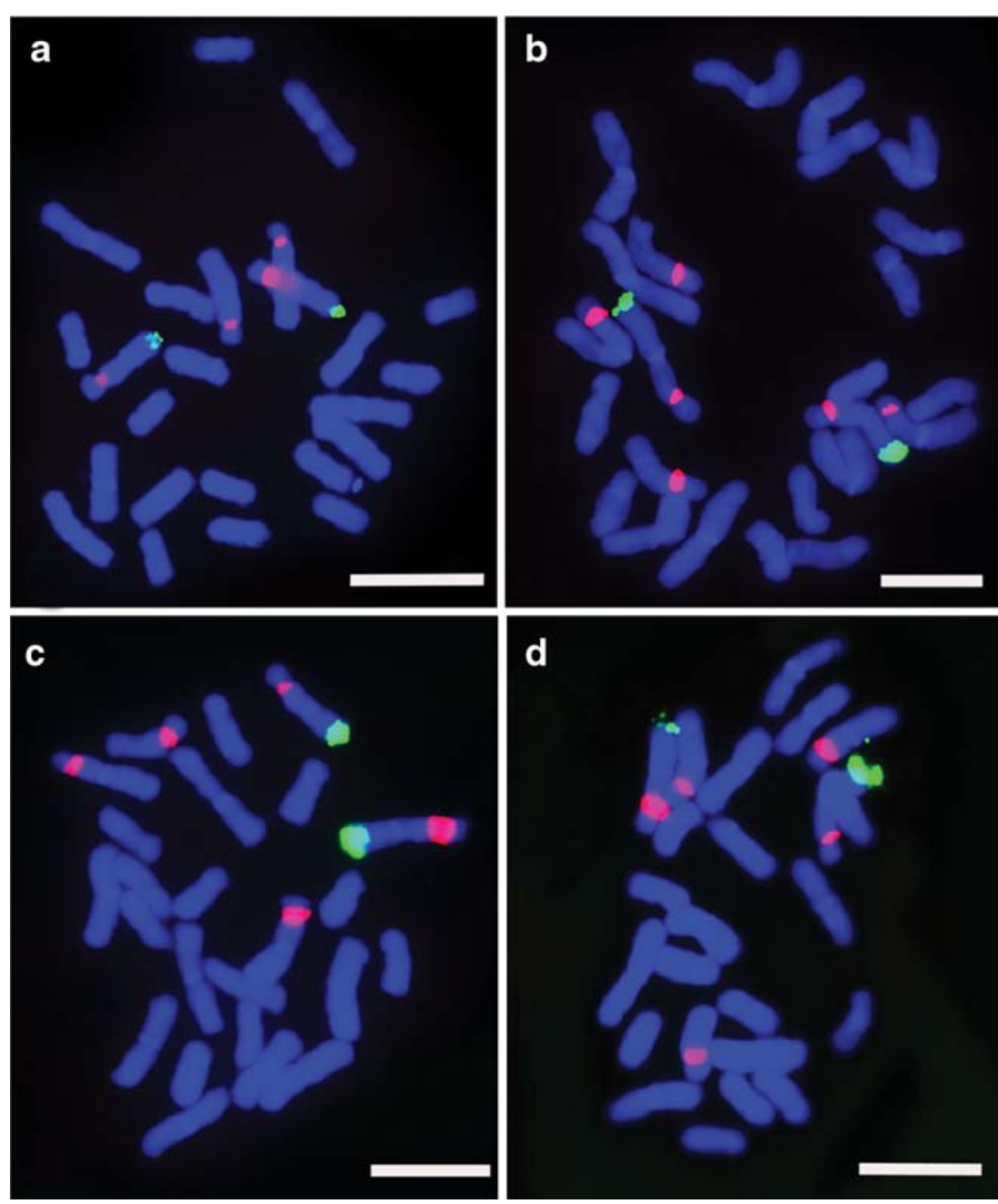

rDNA signals divided regularly into the two daughter cells at anaphase-I. At anaphase-II, the sister chromatids separated and moved towards opposite cell poles (Fig. 3e). Based on the rDNA signals, irregular segregations were also verified. Figure 3, f and g, show one pair of rDNA bearing chromosome forming a bridge at anaphase-I in L. leptolepis $\times$ L. gmelinii and L. gmelinii $\times$ L. leptolepis, respectively. Furthermore, the imbalanced distribution of

Table 1 Numbers of pollen mother cells analyzed and the percentage of cells with specific meiotic abnormalities

\begin{tabular}{|c|c|c|c|c|c|c|c|c|}
\hline \multirow[t]{2}{*}{ Meiotic types } & \multicolumn{2}{|c|}{ L. leptolepis } & \multicolumn{2}{|c|}{ L. gmelinii } & \multicolumn{2}{|c|}{ L. leptolepis $\times$ L. gmelinii } & \multicolumn{2}{|c|}{ L. gmelinii $\times$ L. leptolepis } \\
\hline & $\mathrm{D} / \mathrm{M}$ & A-T & $\mathrm{D} / \mathrm{M}$ & A-T & $\mathrm{D} / \mathrm{M}$ & A-T & $\mathrm{D} / \mathrm{M}$ & A-T \\
\hline $\mathrm{AC}(\%)$ & 0.8 & - & 0.6 & 0 & 1.2 & 1.8 & 2.2 & 1 \\
\hline LAG (\%) & 0 & - & 0 & 0 & - & 2.1 & 0.6 & 2 \\
\hline BRI (\%) & - & 4 & - & 0 & - & 14.5 & - & 16 \\
\hline BIV (\%) & 97.3 & - & 97.5 & & 94.6 & - & 93.2 & \\
\hline UIN (\%) & 0 & - & 0 & 0 & 2.0 & - & 2.0 & - \\
\hline MUL (\%) & 2.7 & - & 2.5 & 0 & 3.4 & - & 4.8 & - \\
\hline Total cells analyzed & 244 & 40 & 261 & 50 & 248 & 138 & 147 & 50 \\
\hline
\end{tabular}

$D$ diakinesis, $M$ metaphase, $A$ anaphase, $T$ telophase, $A C$ ascending chromosomes, $L A G$ laggard chromosomes, BRI bridge, UIN univalent, $M U L$ multivalent $B I V$ bivalent 
Fig. 2 Meiotic cells in pollen mother cells (PMCs) of reciprocal interspecific hybrids between Larix leptolepis with Larix gmelinii (stained with carbolic acid-fuchsin). a Diakinesis of a PMC from L. leptolepis $\times L$. gmelinii showing 12 bivalent configurations. b Metaphase-I of a PMC from $L$. gmelinii $\times L$. leptolepis showing 12 bivalent configurations, which are arranged normally at the metaphase plate. c Diakinesis of a PMC from L. leptolepis $\times L$. gmelinii showing quadrivalent (arrow). d Diakinesis of a PMC from $L$. gmelinii $\times$ L. leptolepis showing a frying pan-shaped trivalent (arrow). e, $\mathbf{f}$ Metaphase-I of a PMC from L. leptolepis $\times$ L. gmelinii and $L$. gmelinii $\times$ L. leptolepis, respectively, showing two univalent, which are scattered outside the plate. g Anaphase-I of a PMC from L. leptolepis $\times$ L. gmelinii showing bridge and fragment (arrows). h Anaphase-I of a PMC from $L$. gmelinii $\times L$. leptolepis showing laggard chromosome (arrow).

i Telophase-I of a PMC from L. leptolepis $\times$ L. gmelinii showing laggard chromosome (arrow). Scale bar=15 um
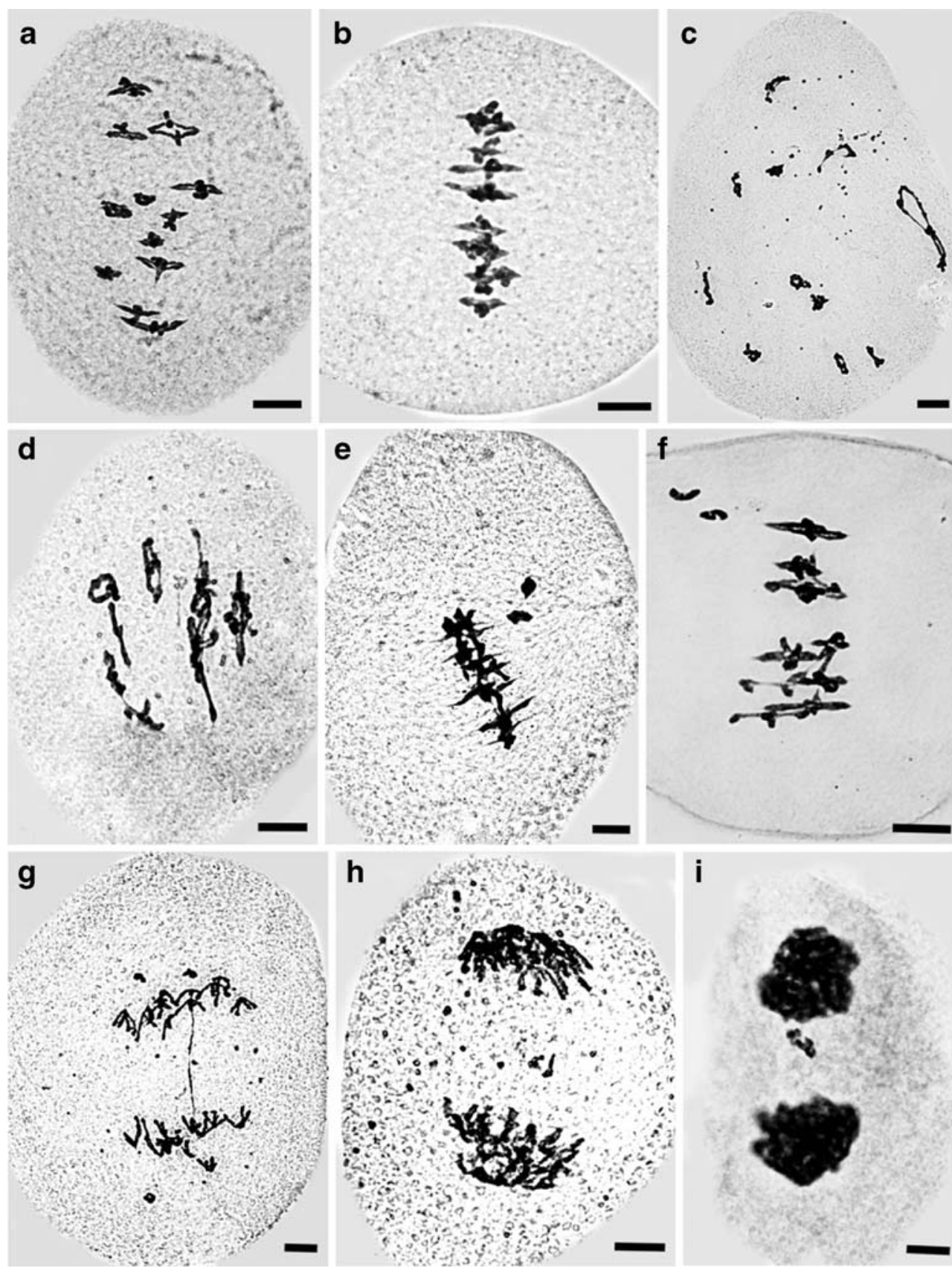

i

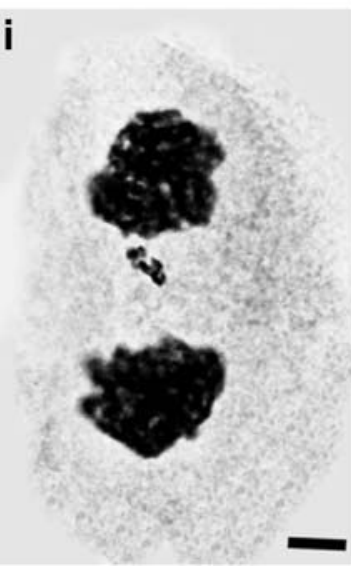

chromosomes carrying 45S rDNA were observed in early telophase-I in some cells (Fig. 3h).

Although the rDNA loci as physical markers provided convincing evidence for matching chromosome homologues between these species, the same GISH conditions failed to discriminate the chromosomes of L. leptolepis and L. gmelinii from each other in meiotic chromosome preparations of these reciprocal hybrids (Fig. 3i). Thus, we were not able to assess the extent of homologous and homoeologous pairing.

\section{Discussion}

Genome relationships between L. leptolepis and L. gmelinii

Evidence from classical and molecular systematics, ecology, and crossing relationships all indicate L. leptolepis and L. gmelinii are closely related sister species (Semerikov and Lascoux 1999; Khatab et al. 2008). This was also confirmed in the present study, where the high frequency of homoeologous chromosome pairing in reciprocal hybrids 
Fig. 3 Fluorescence in situ hybridization to chromosomes of meiotic nuclei of reciprocal interspecific hybrids; 45S rDNA loci and 5S rDNA loci are identified by red and green signals, respectively.

a, b Meiotic metaphase-I of a pollen mother cell (PMC) from Larix leptolepis $\times$ Larix gmelinii and $L$. gmelinii $\times L$. leptolepis, respectively, showing rDNA bearing-chromosomes exclusively formed bivalents. c, $\mathbf{d}$ Two pairs of rDNA bearingchromosomes regularly separated into opposite sides of the cell in L. leptolepis $\times$ L. gmelinii and L. gmelinii $\times$ L. leptolepis, respectively. e Meiotic telophase-II of a PMC from $L$. gmelinii $\times$ L. leptolepis showing sister chromatids regularly divided. f Meiotic anaphase-I of a PMC from L. leptolepis $\times L$. gmelinii showing 45S-5S rDNA bearing-chromosomes formed bridge. g Meiotic anaphase-I of a PMC from $L$. gmelinii $\times L$. leptolepis showing $45 \mathrm{~S}$ rDNA bearing-chromosomes formed bridge. $\mathbf{h}$ Meiotic anaphase-I of a PMC from L. leptolepis $\times L$. gmelinii showing unequal separation of $45 \mathrm{~S}$ rDNA bearingchromosomes. i Genomic in situ hybridization on meiotic metaphase chromosomes of the interspecific species L. leptole$p i s \times L$. gmelinii, using labeled genomic DNA from L. leptolepis as probe (detected with strepetavidin-Cy3, in red). Chromosomes were counterstained with DAPI, in blue. Scale bar $=15$ um
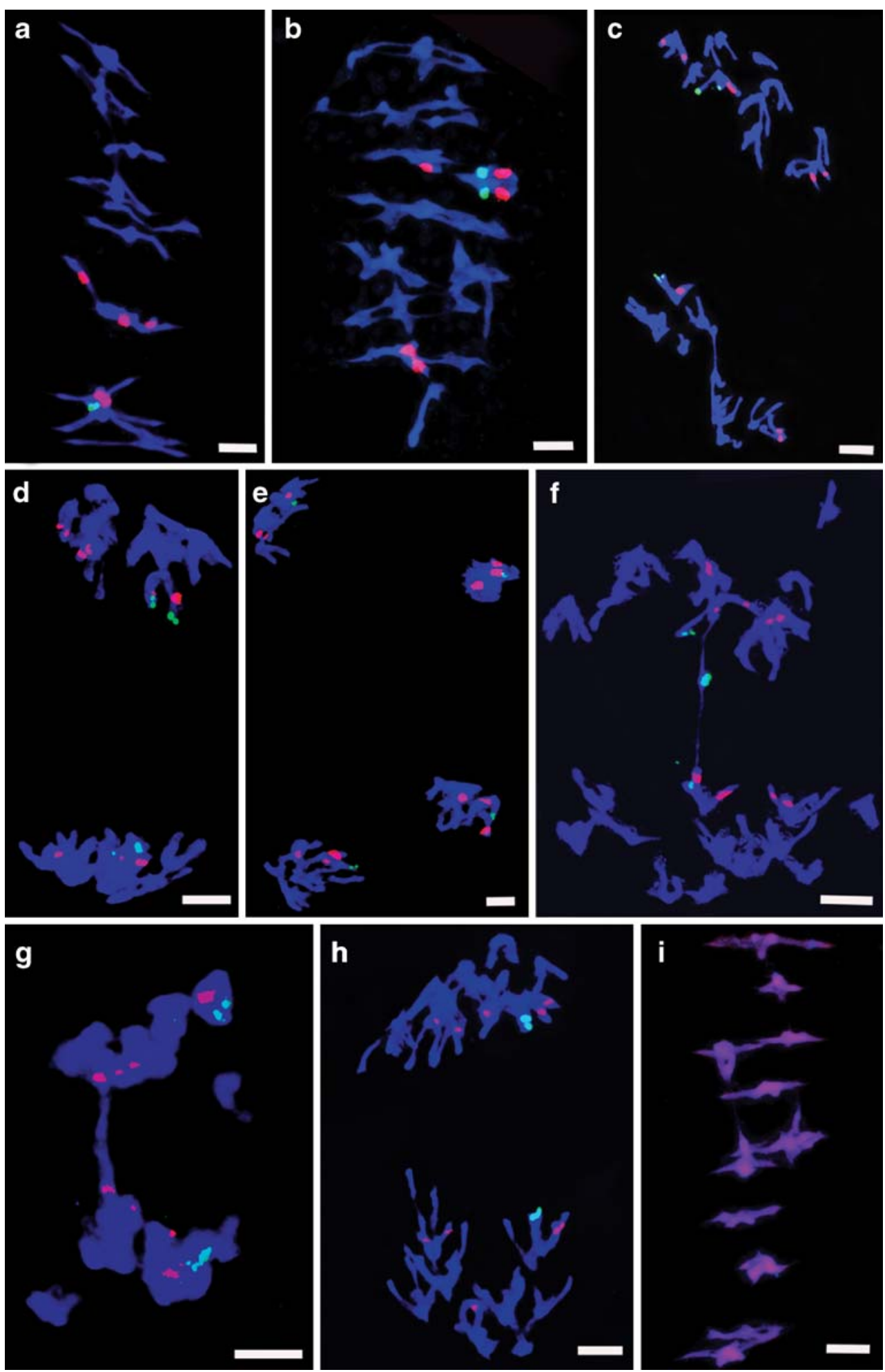

indicated that they shared a high degree of homology. This conclusion was consistent with GISH analysis, in which standard GISH conditions were insufficient to distinguish the recombinant genomes of the hybrids from each other. It was suggested that homology between L. leptolepis and
L. gmelinii was relatively high at the sequence level, at least in terms of dispersed repetitive sequences. In addition, we observed the same distribution patterns and the numbers of $5 \mathrm{~S}$ rDNA loci in the two parental species, as well as the similar chromosomal location of $45 \mathrm{~S}$ rDNA loci. Giving 
that these species also have a number of cytological features in common (Liu et al. 2006), we therefore assumed that the chromosomes of these two parental species within Larix were essentially collinear and homologous. This results presented here also suggest that the overall structures of the genomes of these species have not changed excessively during the course of evolution.

In contrast, the numbers of $45 \mathrm{~S}$ rDNA loci were evidently different between the two parental species, resulting in physically distinct chromosome sets.

\section{Relevance of interspecific hybrids to breeding}

Interspecific hybridization plays an important role in the creation of genetic variability for breeding improvement (Desel et al. 2002). The efficiency of interspecific crosses depends on the level of genetic and structural relatedness between the implicated genomes as high levels of genome similarity are required to ensure appropriate chromosome pairing and genetic recombination (Leflon et al. 2006). Meiotic recombination is essential for information from the parental chromosomes to be combined into new genetic entities that can be passed to the next generation (Puchta and Hohn 1996). In principle, more frequent introgressions are expected when the recombinant genomes share higher levels of similarity (Panestos and Baker 1967; Boudry et al. 1993). Our results showed that the genomes of L. leptolepis and L. gmelinii exhibit high homology at the DNA sequences, which allowed regular pairing and recombination between homoeologous chromosomes at relatively high rate in their hybrids. Cytological observations clearly demonstrated that the two hybrids generally showed regular bivalent formations, indicating that meiotic recombination did occur between the two parental sets of homoeologous chromosomes. In addition, quadrivalents and trivalents occasionally formed in these two reciprocal hybrids suggested that some chromosome interchange events did occur. We also observed several meiotic abnormalities in these hybrids; however, these would be unlikely to not greatly influence breeding or introgression due to their low frequency and a strong selection against abnormal meiotic products in early stages of development.

In conclusion, Larix hybrids may have frequent intergenomic recombination events, and that genes may be readily introgressed into one species from the other in the genus Larix. Interspecific hybridization may be a potential method for genetic improvement in larch.

\section{Implications for identifying hybrids}

Breeding programs involving interspecific hybrids should rely on an accurate system of identification of parental species and certification of their putative hybrids to ensure the delivery of the desired materials and to obtain the predicted genetic gains (Gros-Louis et al. 2005). Although some morphological traits allow identification of Larix species at the mature stage, differentiation is not always possible to distinguish either hybrid seeds or juvenile plants. Therefore, there is a need for the development of reliable markers to distinguish parents and their hybrids. Certain molecular markers have already been developed for some larch species (Bergmann and Ruetz 1987; Scheepers et al. 2000; Acheré et al. 2004; Gros-Louis et al. 2005; Moriguchi et al. 2008), for which hybrids are difficult to detect on the basis of morphology at early stage. However, such studies depend on wide screening for fixed molecular markers or sequences from which the species in question can be diagnosed. It is often time-consuming to find reproducible species-diagnostic molecular markers among larch species as they share a high degree of sequence homology (Nkongolo and Klimaszewska 1995). Another factor suggested to be responsible for this lack of efficiency is genomic reshuffling due to hybridization, which would obscure true interpretation of molecular markers in hybrids.

In contrast, FISH of metaphase chromosomes can enable the unequivocal determination the genomic constitution of hybrid plants (Desel et al. 2002; Markova et al. 2006). Physical mapping by FISH of the tandemly repeated genes encoding the 18S-5.8S-25S ribosomal RNA and 5S ribosomal RNA genes has provided a number of useful chromosome landmarks in larch trees (Lubaretz et al. 1996; Liu et al. 2006). These studies showed that the rDNA organization in Larix varies among species. Thus, if the hybrid has an additive character, molecular cytogenetics of the rDNA genes would offer a relatively efficient way to differentiate varieties in seed orchards or a special breeding program at the level of chromosomes.

The present study reported experiments to assess whether FISH could discriminate hybrids between L. leptolepis and L. gmelinii, which appeared to be especially useful for two reasons. First, no prior genetic information on the species analyzed is required. Second, chromosomal in situ DNA hybridization (ISH) allows the physical sites of DNA sequences to be visualized directly, without regard to polymorphism or coding ability (Crane et al. 1993). Therefore, FISH can serve as a useful tool for identifying hybrids in future breeding programs, as well as a means to analyze the genomes of the genus Larix.

Acknowledgements We are grateful to Guang-Yuan Rao and YanPing Guo for their valuable comments on the manuscript. This work was supported by the National High Technology Research and Development Program of China (Grant Nos. 2006AA100109, 2007AA021403, 2007AA10Z182, 2008AA10Z126, and 2007AA021501), the National Natural Science Foundation of China (Grant Nos. 30571517 and 30830086), and the National Basic Research Program of China (Grant Nos. 2009CB119106 and 2009CB119107). 
Open Access This article is distributed under the terms of the Creative Commons Attribution Noncommercial License which permits any noncommercial use, distribution, and reproduction in any medium, provided the original author(s) and source are credited.

\section{References}

Acheré V, Faivre Rampant P, Pâques LE, Prat D (2004) Chloroplast and mitochondrial molecular tests identify European $\times$ Japanese larch hybrids. Theor Appl Genet 108:1643-1649

Baltunis BS, Greenwood MS, Eysteinsson T (1998) Hybrid vigor in Larix: growth of intra- and interspecific hybrids of Larix deciduas, $L$. laricina, and L. kaempferi after 5-years. Silvae Genet 47:288-293

Bergmann F, Ruetz W (1987) Identification of seed of hybrid larches from seed orchards using as isozyme marker. Silvae Genet 36:102-105

Boudry P, Morchen M, Saumitoulaprade P, Vernet P, Vandijk H (1993) The origin and evolution of weed beets-consequences for the breeding and release of herbicide-resistant transgenic sugar-beets. Theor Appl Genet 87:471-478

Crane CF, Price HJ, Stelly DM (1993) Identification of a homeologous chromosome pair by in situ DNA hybridization to ribosomal RNA loci in meiotic chromosomes of cotton (Gossypium hirsutum). Genome 36:1015-1022

Desel C, Jansen R, Dedong G, Schmidt T (2002) Painting of parental chromatin in beta hybrids by multi-colour fluorescent in situ hybridization. Ann Bot 89:171-181

Doyle JJ, Doyle JL (1990) Isolation of plant DNA from fresh tissue. Focus 12:13-15

Gros-Louis MC, Bousquet J, Pâques LE, Isabel N (2005) Speciesdiagnostic markers in Larix spp. based on RAPDs and nuclear, cpDNA, and mtDNA gene sequences, and their phylogenetic implications. Tree Genet Genomes 1:50-63

Hayashi E, lizuka K, Sukeno S, Kohno K (1998) Relationship between resistance to vole browsing and content of ether extract in the bark of larch species and hybrids. J For Res 3:119-122

Khatab IA, Ishiyama H, Inomata N, Wang XR, Szmidt AE (2008) Phylogeography of Eurasian Larix species inferred from nucleotide variation in two nuclear genes. Genes Genet Syst 83:55-66

Kruklis MV, Milyutin LI (1977) Larix czekanovskii. Nauka, Moscow

Leflon M, Eber F, Letanneur JC, Chelysheva L, Coriton O, Huteau V, Ryder CD, Barker G, Jenczewski E, Chèvre AM (2006) Pairing and recombination at meiosis of Brassica rapa (AA) $\times$ Brassica napus (AACC) hybrids. Theor Appl Genet 113:1467-1480
Leitch IJ, Heslop-Harrison JS (1994) Detection of digoxigenin-labeled DNA probes hybridized to plant chromosomes in situ. Methods Mol Biol 28:177-185

Liu B, Zhang SG, Zhang Y, Lan TY, Qi LW, Song WQ (2006) Molecular cytogenetic analysis of four Larix species by bicolor fluorescence in situ hybridization and DAPI banding. Int J Plant Sci 167:367-372

Lubaretz O, Fuchs J, Ahne R, Meister A, Schubert I (1996) Karyotyping of three Pinaceae species via fluorescent in situ hybridization and computer-aided chromosome analysis. Theor Appl Genet 92:411-416

Markova M, Lengerova M, Ziuvova J, Janousek B, Vyskot B (2006) Karyological analysis of an interspecific hybrid between the dioecious Silene latifolia and the hermaphroditic Silene viscose. Genome 49:373-379

Mikami S (1988) Breeding for wood quality of Japanese larch, Larix kaempferi (Lamb.) Carr. Bull For Tree Bree Inst 6:47-152

Moriguchi Y, Kita K, Uchiyama K, Kuromaru M, Tsumura Y (2008) Enhanced hybridization rates in a Larix gmelinii var. japonica $\times$ L. kaempferi interspecific seed orchard with a single maternal clone revealed by cytoplasmic DNA markers. Tree Genet Genomes 4(9):637-645

Nkongolo KK, Klimaszewska K (1995) Cytological and molecular relationships between Larix deciduas, L. leptolepis and Larix $\times$ eurolepis: identification of species-specific chromosomes and synchronization of mitotic cells. Theor Appl Genet 90:827-834

Panestos CA, Baker H (1967) The origin of variation in wild Raphanus sativus in California. Genetica 38:243-274

Pâques LE (1992) Performance of vegetatively propagated Larix deciduas, L. kaempferi, and L. laricina hybrids. Ann Sci For 49:63-74

Pâques LE (2002) Heterosis in interspecific hybrids between European and Japanese larch. In: Pâques LE (ed) Improvement of larch (Larix sp.) for better growth, stem form and wood quality, INRA. Gap (Hautes-Alpes), Auvergne-Limousin, France, pp 155-163

Puchta H, Hohn B (1996) From centiMorgans to basepairs: homologous recombination in plants. Trends Plant Sci 1:340-348

Rieseberg LH (1997) Hybrid origins of plant species. Annu Rev Ecol Syst 28:359-389

Scheepers D, Eloy MC, Briquet M (2000) Identification of larch species (Larix deciduas, Larix kaempferi and Larix $\times$ eurolepis) and estimation of hybrid fraction in seed lots by RAPD fingerprints. Theor Appl Genet 100:71-74

Semerikov VL, Lascoux M (1999) Genetic relationship among Eurasian and American Larix species based on allozymes. Heredity 83:62-70

Semerikov VL, Semerikov LF, Lascoux M (1999) Intra- and interspecific allozyme variability in Eurasian Larix Mill. species. Heredity 82:193-204 